\title{
Clinical efficacy of nutraceutical diet for cats with clinical signs of cutaneus adverse food reaction (CAFR)
}

\author{
F. Mazzeranghi ${ }^{1 *}$, C. Zanotti $^{1 *}$, A. Di Cerbo ${ }^{2}$, J.P. Verstegen ${ }^{3}$, R. Cocco ${ }^{4}$, \\ G. Guidetti ${ }^{5}$, S. Canello \\ ${ }^{1}$ Ambulatorio Veterinario Fiamma Mazzeranghi \\ Traversa I di via Rudiano 9/e, 25032 Chiari, Brescia, Italy \\ ${ }^{2}$ Department of Medical, Oral and Biotechnological Sciences, Dental School, \\ University "G. d'Annunzio" of Chieti-Pescara, Via dei Vestini 31, 66100 Chieti, Italy \\ ${ }^{3}$ University of Madison Wisconsin, Madison, Department of Veterinary Medicine, WI 53706, USA \\ ${ }^{4}$ Department of Pathology and Veterinary Clinic, Faculty of Veterinary Medicine, \\ University of Sassari, Sassari, Italy \\ ${ }^{5}$ SANYpet S.p.a., Research and Development Department, Via Austria 3, 35023 Bagnoli di Sopra, Padua, Italy \\ ${ }^{6}$ Forza10 USA Corp., Research and Development Department, Orlando, \\ 6450 Kingspointe Pkwy Orlando Fl 32819, USA
}

\begin{abstract}
Food allergies and food intolerances are clinically difficult to discriminate. Most often, along with cutaneous adverse food reactions or CAFR, they are classified as adverse food reactions, whose causes are numerous, including toxic compounds.

Eighteen indoor-housed domestic cats with evident clinical symptoms related to CAFR (drooling, back and neck intense itching, neck eczema, chronic conjunctivitis and stomatitis) involving skin lesions were studied. Cytological evaluations of ear, skin and gingival swabs revealed an increased turnover of keratinocytes while the oxytetracycline ELISA determination showed an unexpected high amount of oxytetracycline in all cats at the first visit. All cats were then randomly assigned to receive a standard (SD group) or a nutraceutical diet (ND group) for 60 days.

In the ND group a significant reduction of the mean serum concentration of oxytetracycline, pruritus intensity and skin lesion severity $\left({ }^{* *} p<0.01,{ }^{* * *} p<0.001\right.$, and ${ }^{* * *} p<0.001$, respectively) was observed after 60 days, and associated with a significant improvement in the clinical picture.

Although a direct correlation between oxytetracycline presence within cat sera and CAFR-related symptoms has never been described, this study highlights the benefit of a specific nutraceutical diet supplementation in improving clinical symptoms and skin lesions in cats with CARF.
\end{abstract}

Key words: cutaneous adverse food reactions, oxytetracycline, cat

Correspondence to: A. Di Cerbo, e-mail: Alessandro811@hotmail.it, tel.: +393923731318

* These authors contributed equally 


\section{Introduction}

Food allergy refers to a clinical syndrome caused by an acute or chronic immunological reaction following food ingestion, while food intolerance is a non-immunological abnormal physiological response towards some specific foods or food additives. Due to their often-difficult differentiation, these phenomena are generally included in the generic non-specific adverse food reaction syndrome, which can also involve the cutaneous system and are most often referred to as cutaneous adverse food reactions or CAFR. Although there is a lack of well-documented cases of skin-related food intolerance in dogs and cats, dermatological signs seem to be frequent. However, these can often be confused with pyoderma, pruritic exudative dermatoses or "hot spots" (Roudebush et al. 2000, Verlinden et al. 2006).

A typical clinical feature of CAFR in cats is the onset of non-seasonal head and neck pruritus, which may occur in animals from 3 months to 11 years with irregular occurrence depending on many factors, including the diet administered to the animals (White and Sequoia, 1989, Carlotti et al., 1990). Other clinical signs of CAFR include eosinophilic granuloma complex lesions, miliary dermatitis and symmetrical alopecia as a consequence of excessive grooming (Guagumre, 1993).

A recent paper from Mueller et al. (2016) reviewed and suggested some food allergens as mostly contributing to CAFR in cats, e.g. beef, fish and chicken (Mueller et al. 2016). The large variety of protein sources led the authors to assume that these numerous different types of food could act as carriers of similar compounds, including antibiotics and hormones, which might in fact represent the real cause for the onset of dermatological symptoms in those animals particularly sensitive. The potential role of pharmacologically active substances, in particular tetracyclines and their metabolites present in meats and meat-based foods (Chi et al. 2014) was proposed and subsequently discussed.

Due to the lack of clinical evidence concerning the efficacy of pet food to treat CAFR in cats, we aimed to ascertain the role of a specific, commercially available nutraceutical diet in relieving the symptoms of CAFR such as drooling, back and neck intense itch, neck eczema, chronic conjunctivitis and stomatitis in 18 indoor-housed cats. We also attempted to correlate the concentration of oxytetracycline in the sera of the animals with the onset and disappearance of the aforementioned symptoms.
The nutraceutical diet proposed in this study consisted of a mixed formula of fish hydrolysed proteins (from wild caught anchovies free of oxytetracycline), rice carbohydrates, Aloe vera, Arctium lappa, Malva sylvestris, Ribes nigrum, Allium sativum and Omega3/6 fatty acids (1:3 ratio).

Some literature reports have already evidenced the effectiveness of Aloe vera gel and Aloe vera/olive oil combination cream in relieving scabietic and chronic pruritic skin lesions, respectively (Oyelami et al. 2009, Panahi et al. 2012). However, according to a recent paper from Sidgwick et al. (2015), there is still limited clinical evidence of the efficacy of Aloe vera, as well as vitamin $\mathrm{E}$ and $\mathrm{D}$, to support its efficacy in completely restoring skin scarring (Sidgwick et al. 2015). Itch relief has been also observed for Arctium lappa but in the form of herbal moisturising cream (Lee et al. 2013). We demonstrated, for the first time, the effectiveness of a nutraceutical diet with Aloe vera, Arctium lappa, Malva sylvestris, Ribes nigrum, Allium sativum and Omega3/6 fatty acids in canine models suffering from atopic dermatitis and chronic otitis externa (Di Cerbo et al. 2014b, Di Cerbo et al. 2016a). We also recently reported the anti-inflammatory and immune-modulatory effect of Aloe vera alone (Guidetti et al. 2016) and in combination with other botanicals (Cortese et al. 2015, Destefanis et al. 2016).

\section{Materials and Methods}

Eighteen client-owned indoor-housed neutered cats of different breeds (mean age \pm SEM, 6.55 \pm 0.95 year and mean weight $\pm \mathrm{SEM}, 4.01 \pm 0.14 \mathrm{Kg}$; $55.6 \%$ males, $44.4 \%$ females) with evident clinical symptoms related to CAFR (drooling, back and neck intense itch, neck eczema, chronic conjunctivitis and stomatitis) were evaluated.

The animals were randomly divided and assigned to receive either the nutraceutical diet (ND group, $\mathrm{n}=9$ ) or a standard diet (SD group, $\mathrm{n}=9$ ) once a day for 60 days, following the manufacturer's recommendations.

In addition, 6 out of 18 cats that showed a critical clinical picture with extended lesions were preventively pharmacologically treated with a single subcutaneous injection of an antimicrobial (CONVENIA, Zoetis Belgium SA, Belgium) and a corticosteroid (DEXADRESON FORTE, MSD Animal Health srl, Milan, Italy) before being equally allocated to the 2 groups. 


\section{The diets}

Both nutraceutical and control diet fulfilled the recommendations for crude protein $(31 \%)$, crude oils and fats (15\%), crude ash (7.7\%), moisture (8\%) and a Metabolized Energy (ME) of $3.620 \mathrm{kcal} / \mathrm{kg}$ (or 15.2 $\mathrm{MJ} / \mathrm{kg}$ ), according to the Nutritional Guidelines for complete and complementary pet food for cats and dogs. Moreover, the diets were in the form of kibbles industrially produced with the same amount of vitamins (A, and E), trace elements (Choline chloride, Zinc sulphate monohydrate, and Cupric chelate glycine hydrate) and amino acids (DL-methionine) (Table 1).

Table 1. Vitamins, essential fatty acids, trace elements and amino acids amount per $\mathrm{kg}$ of complete food in ND and SD diet.

\begin{tabular}{cc}
\hline Essential fatty acids & Amount per kg of diet \\
\hline Omega6 & $39 \mathrm{~g} / \mathrm{kg}$ \\
\hline Omega3 & $13 \mathrm{~g} / \mathrm{kg}$ \\
\hline Vitamins \\
\hline Vitamin A & $28000 \mathrm{UI} / \mathrm{kg}$ \\
\hline Vitamin E & $120 \mathrm{mg} / \mathrm{kg}$ \\
\hline Trace elements & $1000 \mathrm{mg} / \mathrm{kg}$ \\
\hline Choline chloride & $75 \mathrm{mg} / \mathrm{kg}$ \\
\hline Zinc sulphate monohydrate & $15 \mathrm{mg} / \mathrm{kg}$ \\
\hline Cupric chelate glycine hydrate \\
\hline Amino acids \\
\hline DL-methionine \\
\hline
\end{tabular}

In addition, the ND was characterized by the presence of cold-pressed tablets composed by $60-80 \%$ of fish and vegetable hydrolyzed protein, $20-40 \%$ of minerals used as glidants and nutraceutical substances: Aloe vera, Arctium lappa, Malva sylvestris, Ribes nigrum, Allium sativum (Table 2).

Table 2. Nutraceutical substances amount per $\mathrm{kg}$ of complete food in ND diet.

\begin{tabular}{cc}
\hline Nutraceutical substances & $\begin{array}{c}\text { Amount per } \mathrm{kg} \\
\text { of complete food }\end{array}$ \\
\hline Aloe vera & $112 \mathrm{mg} / \mathrm{kg}$ \\
\hline Arctium lappa & $150 \mathrm{mg} / \mathrm{kg}$ \\
\hline Malva sylvestris & $52 \mathrm{mg} / \mathrm{kg}$ \\
\hline Ribes nigrum & $90 \mathrm{mg} / \mathrm{kg}$ \\
\hline Allium sativum & $241 \mathrm{mg} / \mathrm{kg}$ \\
\hline
\end{tabular}

\section{Clinical evaluation}

Cats received veterinary inspections before intervention, after 20 days, and at the end of the intervention after 60 days.

The work was performed in compliance with national and international regulations (Italian regulation D.L.vo 116/1992 and European Union regulation 86/609/EC) for procedures and animal care. The recommendations of the ARRIVE in animal research were also considered (Kilkenny et al. 2012).

Before diet study initiation and at the end of the 60-day period, $4 \mathrm{~mL}$ of blood were drawn from each cat and analyzed using a tetracycline specific ELISA kit for pets (Cat. \# DE - 100430, Genemed Synthesis, Inc., San Antonio, USA).

At the first inspection before the study initiation, a gingival, ear and dermal swab was done for each cat, rolled over a microscope slide and allowed to dry before staining with Diff-Quik stain (Mercedes Medical, Sarasota, FL, USA) (Jackson et al. 2013).

A picture of each cat before, after 20 days and after 60 days dietary intervention was acquired to evaluate and characterize the skin and the lesion type.

\section{Lesion evaluation}

The severity and the extent of each lesion was scored using a numerical rating scale with five degrees of severity $(0=$ none, $1=$ very mild, $2=$ mild, $3=$ moderate, $4=$ severe $)$ and were assessed before and at the end of the study (Steffan et al. 2012).

\section{Pruritus evaluation}

To assess the pruritus severity a five-point numerical VAS scale was used throughout the study based on cat behavior $(0=$ the cat was comfortable, grooming like any normal cat; $1=$ the cat was grooming, but the pruritus was tolerable and the cat remained calm; $2=$ the cat was grooming, but it was generally tolerable; $3=$ the cat was grooming quite often, the cat was uncomfortable, nervous or often agitated; $4=$ the cat was uncomfortable, grooming all the time) (Steffan et al. 2012).

\section{Statistical analysis}

Data were analysed using GraphPad Prism 6 software (GraphPad Software, Inc., La Jolla, CA, USA). All data are presented as means \pm standard error of the mean. Differences in serum oxytetracycline 


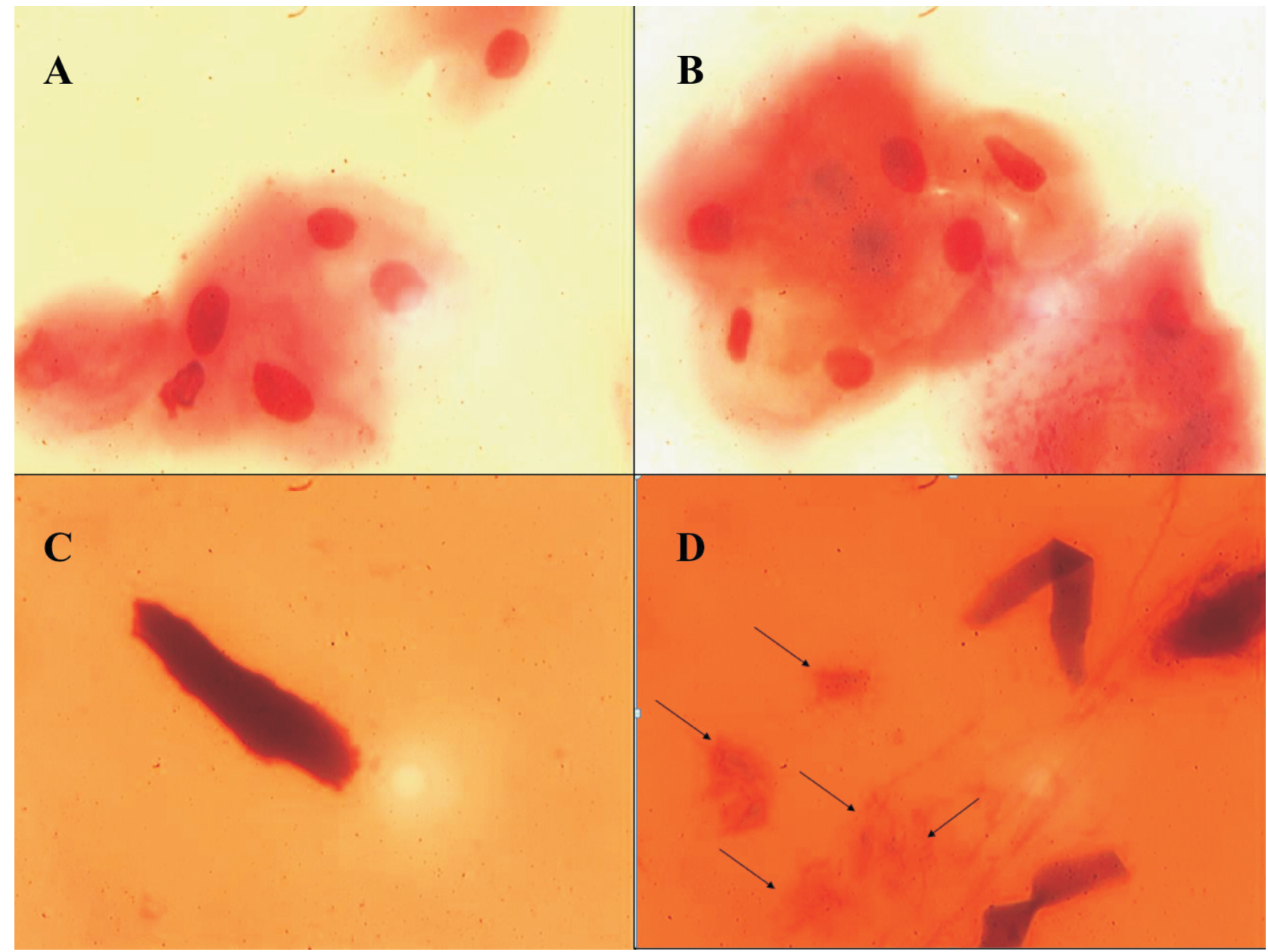

Fig. 1. Microscopic image of (A, B) gingival swab with giant intermediate squamous epithelial cells with pink-colored abundant cytoplasm where oral bacterial strains can adhere; (C) ear swab with a papyrus-like enrolled elongated lanceolate corneocyte; (D) dermal swab with squamous epithelial cells with pyknotic nucleus (arrows) and a papyrus-like enrolled elongated lanceolate corneocyte.

concentration, skin lesion severity and pruritus intensity before and at the end of the evaluation period were analyzed using a two-way analysis of variance (ANOVA) followed by Sidak's multiple comparisons test. A * $p<0.05$ was considered significant.

\section{Results}

Cytological evaluations revealed a massive presence of corneocytes in all of the skin and ear swabs of cats (Fig. 1C,D). The presence of a high number of keratinocytes with a nucleus and the almost complete lack of neutrophils in all cats indicates that the lesions derived from an exfoliative process, due to an increased epithelial turnover, rather than an inflammatory condition (Fig. 1A,B) generally associated with a large number of inflammatory cells. No inflammatory cells, such as granulocytes and neutrophils, were observed with the exception of one cat in the ND group.
In the ND group a significant decrease in tetracycline serum concentration was observed from initial values of $108.30 \pm 2.88 \mathrm{ng} / \mathrm{ml}$ to $88.78 \pm 4.37$ $\mathrm{ng} / \mathrm{ml}$ after 60 days of treatment. No significant differences were observed in the SD group (Fig 2A, $\left.{ }^{* *} p<0.01\right)$. As concerns the pruritus intensity, the score significantly decreased from a baseline value of $3.33 \pm 0.23$ to $1.66 \pm 0.16$ in the ND group. No significant differences were observed in the SD group (Fig. 2B, ${ }^{* * *} p<0.001$ ).

Skin lesion severity of the ND group also significantly decreased after 60 days of evaluation, with respect to the baseline; the score decreased from a baseline value of $3.44 \pm 0.17$ to $1.44 \pm 0.17$. No significant differences were observed in the SD group (Fig. 2C, $\left.{ }^{* * *} p<0.001\right)$.

All cats belonging to the ND group improved their dermatological status already after 20 days diet supplementation; however, their clinical picture, including skin lesions and pruritus intensity, significantly improved toward the end of the study (Fig. 3). 

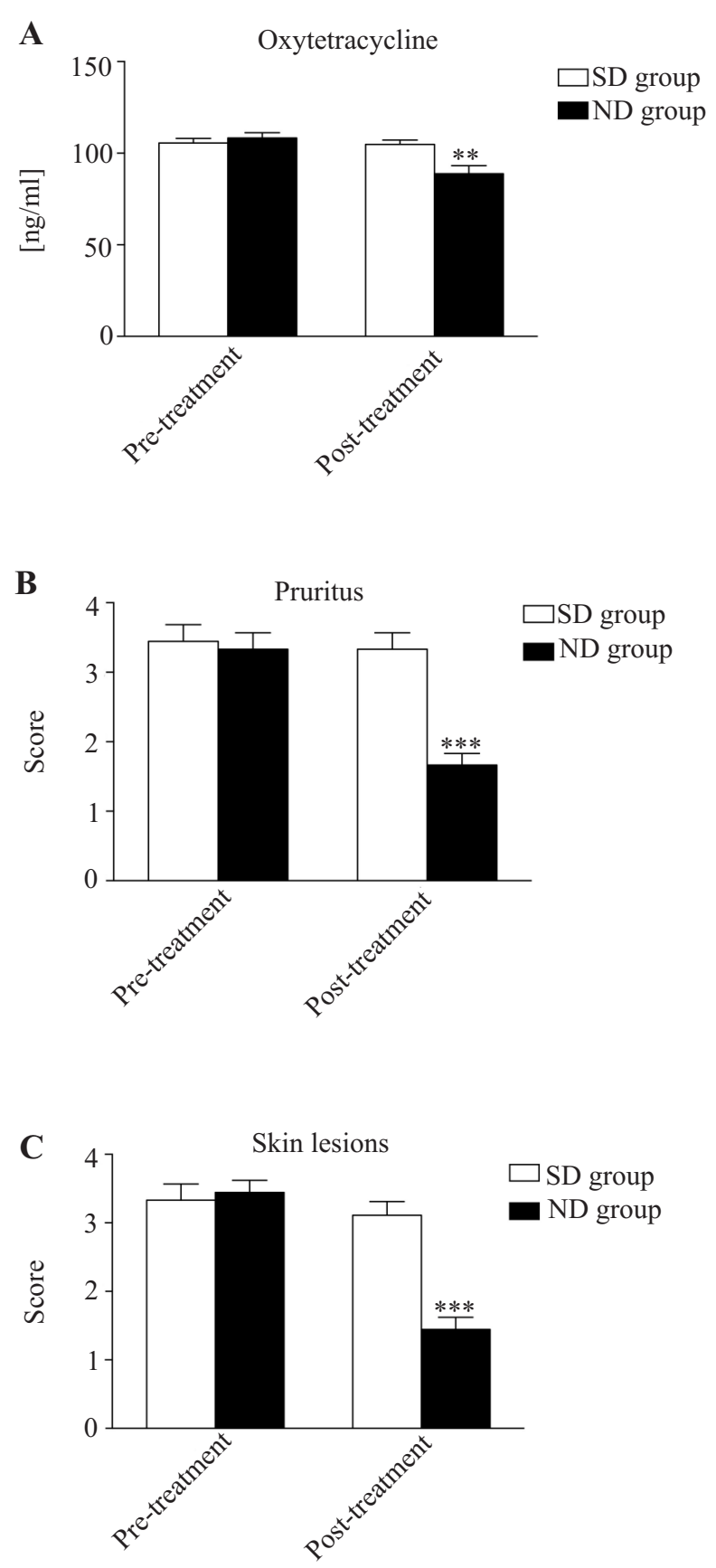

Fig 2. Graphical representation of (a) oxytetracycline serum concentration (b) pruritus intensity, and (c) skin lesions severity, before and after 60 days of SD or ND supplementation, a significant decrease of each parameter was observed in ND group $\left({ }^{* *} p<0.01 ;{ }^{* * *} p<0.001\right.$ and ${ }^{* * *} p<0.001$, respectively).

\section{Discussion}

Results evidenced the effectiveness of the ND, free of oxytetracycline, in restoring the normal dermal physiological homeostasis in cats with evident clinical symptoms related to CAFR (drooling, back and neck intense itch, neck eczema, chronic conjunctivitis and stomatitis). In the present study, all cats presented lesions characterised by exfoliative dermatitis. Exfoliative dermatitis is characterized by a generalized severe squamation and can be caused by pharmacological agents and food allergies (Scott, 1988, Miller et al. 2013).

Normal epidermal turnover is approximately of 22 days (Baker et al. 1973). It has been demonstrated that turnover time significantly decreases to 15 days after dermal stress, i.e. hair cut (Baker et al. 1974) and surgically-induced wounds, where epidermal mitotic activity results increased (Miller et al. 2013). A turnover time decrease to 7 days has been also observed in Cocker Spaniels and Irish Setters affected by seborrheic skin (Baker and Maibach 1987).

In the present study, treatment with the neutraceutical oxytetracyline-free diet was associated with a significant improvement in the skin conditions prealably observed in the animals. As already demonstrated, a 6 to 8 week restrictive elimination trial is needed to allow the diagnosis of CAFR in $90 \%$ of the animals confirming our diagnostic working hypothesis (Olivry et al. 2015). This dramatic improvement may be related to the decrease in serum concentration of oxytetracycline discussed below or with the use of the specific neutraceutical diet administered (or both). This certainly requires further investigation.

We recently identified a specific compound, oxytetracycline, as the possible underlying cause of most inflammatory pathologies both in vitro (Odore et al. 2015, Di Cerbo et al. 2016b, Guidetti et al. 2016, Gallo et al. 2017) and in vivo (Di Cerbo et al. 2014a, Di Cerbo et al. 2014b, Di Cerbo et al. 2015, Di Cerbo et al. 2016a, Di Cerbo et al. 2017). To the best of our knowledge there is no clinical evidence of the effectiveness of other commercially available pet diets able to simultaneously exert an anti-inflammatory and re-epithelializating activity.

Although the overall recovery of CAFR symptoms can be mainly ascribed to the combined activity of hydrolyzed proteins, omega fatty acids $3 / 6$ and botanicals present within the nutraceutical diet, we speculate that oxytetracycline may play a role in the cause of the CAFR clinical signs observed in the animals included in this study. Indeed, at initiation of the evaluation, all 18 animals had a significant blood concentration of oxytetracycline, which significantly decreased once fed the oxytetracycline-free neutraceutical diet.

Oxytetracycline belongs to the class of tetracyclines which are the most widely and legally used antibiotics in intesive farming, e.g. poultry (Palmieri et al. 2014, Odore et al. 2015), livestock (Kimera et al. 2015) and aquaculture (Chuah et al. 2016), due to their low cost and efficacy (Chopra and Roberts, 2001). Unfortunately oxytetracycline has also a high affinity for calcium-rich tissues such as bone and teeth 


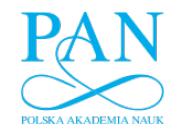
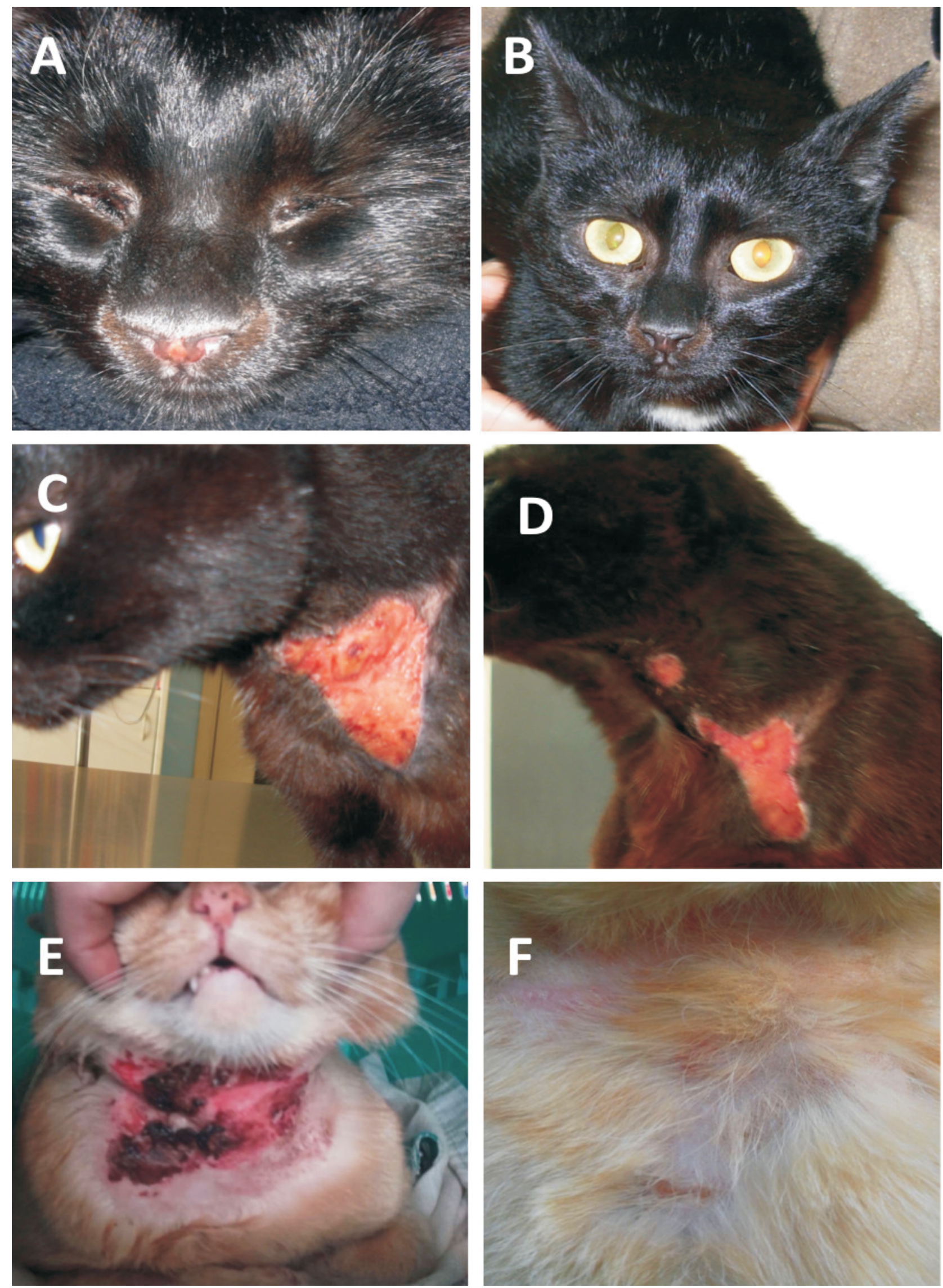

Fig. 3. Dermatological improvements of cats belonging to ND group before (A-C-E) and after (B-D-F) 60 days of diet supplementation. 
(Milch et al. 1957) and can remain fixed for extended periods in treated animals even respecting withdrawal times (Odore et al. 2015). Moreover, pet food production relies on meal (mainly poultry) by-products (Maine et al. 2015) in which an important percentage of bone meal $(20-30 \%)$ is present. This mix very often drags behind oxytetracycline residues that are present in commercially available diets (canned, semi-moist and dry) and can accumulate within the pet's body.

Recently, the toxicity of milled bone from chickens treated with oxytetracycline at $20 \%$, according to law standards, compared to bone specimen from untreated animals was demonstrated (Odore et al. 2015).

These observations allow us to speculate about the potential toxicity of poultry derivatives which are oxytetracycline loaded and chronically consumed by companion animals, and pave the way for a new concept of food sensitization associated with the presence of oxytetracycline contaminants acting as the main enhancers of inflammatory processes, which typically characterize skin and gastrointesinal diseases.

Although the Food and Drug Administration (Headquarters 2012) and World Health Organization (Agency 2014) have recently established maximum residue limits in foods, antibiotic residues in foods may still be present (Graham et al., 2014) thus explaining the persistence of dermatological manifestations in our cohort of cats. This is particularly true as international regulations do not impose an antibiotic concentration evaluation in bones and fat, making pet food including these residues potentially dangerous (Communities 1996).

This work deserves further evaluations however introduces already a worning statement concerning the presence of toxic antibiotics in food. They may indeed underlie or contribute to the etiopathogenesis of certain disorders or syndromes, usually ascribed to other causes or confused with allergic or intolerance syndromes or idiosyncrasies.

Taken together these data partially suggest a causative relation between some toxic compound including oxytetracycline residues and the impressive number of clinical cases, daily observed in our pet population. Their increased frequency over the last 20 years may eventually be related, with other causative toxic factors, to the continuous and overall increase in the consumption of packaged meat and meat by-products used for petfood production including snacks, treats, chews and biscuits. This hypothesis requires further research and evaluation.

\section{Acknowledgments}

None of Authors has financial or personal relationships with other people or organizations and data interpretation was totally free from specific interests and the study has not been conditioned by any bias that could affect the results. This research was performed in collaboration with some scientists from the Division of Research and Development, Sanypet SpA, Padova, Italy (as indicated in the Author's affiliation) according to scientific and ethical principles of the scientific community.

\section{References}

Baker BB, Maibach HI (1987) Epidermal Cell Renewal In Seborrheic Skin Of Dogs. Am J Vet Res 48: 726-728.

Baker BB, Maibach HI, Park RD (1974) Epidermal Cell Renewal In Dogs After Clipping Of The Hair. Am J Vet Res 35: 445-446.

Baker BB, Maibach HI, Park RD, McFarland LZ, O'Brien TR (1973) Epidermal Cell Renewal In The Dog. Am J Vet Res 34: 93-94.

Carlotti DN, Remy I, Prost C (1990) Food Allergy In Dogs And Cats. A Review And Report Of 43 Cases. Vet Dermatol 1: 55-62.

Chi Z, Liu R, You H, Ma S, Cui H, Zhang Q (2014) Probing The In Vitro Cytotoxicity Of The Veterinary Drug Oxytetracycline. Plos One 9: E102334.

Chopra I, Roberts M (2001) Tetracycline Antibiotics: Mode Of Action, Applications, Molecular Biology, And Epidemiology Of Bacterial Resistance. Microbiol Mol Biol Rev 65: 232-60; Second Page, Table Of Contents.

Chuah LO, Effarizah ME, Goni AM, Rusul G (2016) Antibiotic Application And Emergence Of Multiple Antibiotic Resistance (MAR) In Global Catfish Aquaculture. Curr Environ Health Rep 3: 118-127.

Cortese L, Annunziatella M, Palatucci AT, Lanzilli S, Rubino V, Di Cerbo A, Centenaro S, Guidetti G, Canello $S$, Terrazzano G (2015) An Immune-Modulating Diet Increases The Regulatory T Cells And Reduces T Helper 1 Inflammatory Response In Leishmaniosis Affected Dogs Treated With Standard Therapy. BMC Vet Res 11: 295.

Destefanis S, Giretto D, Muscolo MC, Di Cerbo A, Guidetti G, Canello S, Giovazzino A, Centenaro S, Terrazzano G (2016) Clinical Evaluation Of A Nutraceutical Diet As An Adjuvant To Pharmacological Treatment In Dogs Affected By Keratoconjunctivitis Sicca. BMC Vet Res 12: 214.

Di Cerbo A, Canello S, Guidetti G, Laurino C, Palmieri B (2014)a. Unusual Antibiotic Presence In Gym Trained Subjects With Food Intolerance; A Case Report. Nutr Hosp 30: 395-398.

Di Cerbo A, Centenaro S, Beribe F, Laus F, Cerquetella M, Spaterna A, Guidetti G, Canello S, Terrazzano G (2016)a. Clinical Evaluation Of An Antiinflammatory And Antioxidant Diet Effect In 30 Dogs Affected By Chronic Otitis Externa: Preliminary Results. Vet Res Commun 40: 29-38.

Di Cerbo A, Palatucci AT, Rubino V, Centenaro S, Giovazzino A, Fraccaroli E, Cortese L, Ruggiero G, Guidetti G, Canello S, Terrazzano G (2016)b. Toxicological Implications And Inflammatory Response In Human Lym- 
phocytes Challenged With Oxytetracycline. J Biochem Mol Toxicol 30: 170-177.

Di Cerbo A, Palmieri B, Chiavolelli F, Guidetti G, Canello $S$ (2014)b. Functional Foods In Pets And Humans. Intern J Appl Res Vet Med 12: 192-199.

Di Cerbo A, Pezzuto F, Canello S, Guidetti G, Palmieri B (2015). Therapeutic Effectiveness Of A Dietary Supplement For Management Of Halitosis In Dogs. J Vis Exp E52717.

Di Cerbo A, Sechi S, Canello S, Guidetti G, Fiore F, Cocco R (2017). Behavioral Disturbances: An Innovative Approach to Monitor the Modulatory Effects of a Nutraceutical Diet. J Vis Exp 119: 54878.

Graham F, Paradis L, Begin P, Paradis J, Babin Y, Des Roches A (2014). Risk Of Allergic Reaction And Sensitization To Antibiotics In Foods. Ann Allergy Asthma Immunol 113: 329-330.

Guagumre E (1993). Food Intolerance In Cats With Cutaneous Manifestations. PMCAC 28: 451-460.

Guidetti G, Di Cerbo A, Giovazzino A, Rubino V, Palatucci AT, Centenaro S, Fraccaroli E, Cortese L, Bonomo MG, Ruggiero G, Canello S, Terrazzano G (2016). In Vitro Effects Of Some Botanicals With Anti-Inflammatory And Antitoxic Activity. J Immunol Res 2016: 5457010.

Food and Agriculture Organization Headquarters (2012). Maximum Residue Limits For Veterinary Drugs In Foods. Codex Alimentarius Commission. 35th Session. Ftp://Ftp.Fao.Org/Codex/Weblinks/MRL2_E_2012.Pdf.

Gallo A, Landi R, Rubino V, Di Cerbo A, Giovazzino A, Palatucci AT, Centenaro S, Guidetti G, Canello S, Cortese L, Ruggiero G, Alessandrini A, Terrazzano G (2017). Oxytetracycline induces DNA damage and epigenetic changes: a possible risk for human and animal health? Peer J 5: e3236.

Jackson DE, Selting KA, Spoor MS, Henry CJ, Wiedmeyer CE (2013). Evaluation Of Fixation Time Using Diff-Quik For Staining Of Canine Mast Cell Tumor Aspirates. Vet Clin Pathol 42: 99-102.

Kilkenny C, Browne WJ, Cuthill IC, Emerson M, Altman DG (2012). Improving Bioscience Research Reporting: The ARRIVE Guidelines For Reporting Animal Research. Osteoarthritis Cartilage 20: 256-260.

Kimera ZI, Mdegela RH, Mhaiki CJ, Karimuribo ED, Mabiki F, Nonga HE, Mwesongo J (2015). Determination Of Oxytetracycline Residues In Cattle Meat Marketed In The Kilosa District, Tanzania. Onderstepoort J Vet Res 82: 911.

Lee DH, Seo ES, Hong JT, Lee GT, You YK, Lee KK, Jo GW, Kim NK (2013). The Efficacy And Safety Of A Proposed Herbal Moisturising Cream For Dry Skin And Itch Relief: A Randomised, Double-Blind, Placebo-Controlled Trial-Study Protocol. BMC Complement Altern Med 13: 330 .

Maine IR, Atterbury R, Chang KC (2015). Investigation Into The Animal Species Contents Of Popular Wet Pet Foods. Acta Vet Scand 57: 7.

Milch RA, Rall DP, Tobie JE (1957). Bone Localization Of The Tetracyclines. J Natl Cancer Inst 19: 87-93.

Miller WH, Griffin CE, Campbell KL (2013). Muller And Kirk's Small Animal Dermatology, Elsevier Health Sciences. pp 938.

Mueller RS, Olivry T, Prelaud P (2016). Critically Appraised Topic On Adverse Food Reactions Of Companion Ani- mals (2): Common Food Allergen Sources In Dogs And Cats. BMC Vet Res 12: 9.

Odore R, De Marco M, Gasco L, Rotolo L, Meucci V, Palatucci AT, Rubino V, Ruggiero G, Canello S, Guidetti G, Centenaro S, Quarantelli A, Terrazzano G, Schiavone A (2015). Cytotoxic Effects Of Oxytetracycline Residues In The Bones Of Broiler Chickens Following Therapeutic Oral Administration Of A Water Formulation. Poult Sci 94: 1979-1985.

Olivry T, Mueller RS, Prelaud P (2015). Critically Appraised Topic On Adverse Food Reactions Of Companion Animals (1): Duration Of Elimination Diets. BMC Vet Res, 11: 225 .

Oyelami OA, Onayemi A, Oyedeji OA, Adeyemi LA (2009). Preliminary Study Of Effectiveness Of Aloe Vera In Scabies Treatment. Phytother Res 23: 1482-1484.

Palmieri B, Di Cerbo A, Laurino C (2014). Antibiotic Treatments In Zootechnology And Effects Induced On The Food Chain Of Domestic Species And, Comparatively, The Human Specie. Nutr Hosp 29: 1427-1433.

Panahi Y, Davoudi SM, Sahebkar A, Beiraghdar F, Dadjo Y, Feizi I, Amirchoopani G, Zamani A (2012). Efficacy Of Aloe Vera/Olive Oil Cream Versus Betamethasone Cream For Chronic Skin Lesions Following Sulfur Mustard Exposure: A Randomized Double-Blind Clinical Trial. Cutan Ocul Toxicol 31: 95-103.

Roudebush P, Guilford WG, Shanley KJ (2000). Adverse Reactions To Food. In: Hand MS, Thatcher CD, Remillard RL, Roudebush P. (Ed.) Small Animal Clinical Nutrition. Missouri: Mark Morris Institute. pp 1192.

Scott DW (1988). Exfoliative Dermatoses In A Dog And A Cat Resembling Large Plaque Parapsoriasis In $\mathrm{Hu}-$ mans. Companion Animal Practice 2: 22-29.

Sidgwick GP, McGeorge D, Bayat A (2015). A Comprehensive Evidence-Based Review On The Role Of Topicals And Dressings In The Management Of Skin Scarring. Arch Dermatol Res 307: 461-477.

Steffan J, Olivry T, Forster SL, Seewald W (2012). Responsiveness And Validity Of The SCORFAD, An Extent And Severity Scale For Feline Hypersensitivity Dermatitis. Vet Dermatol 23: 410-E77.

The Commission of the European Communities (1996) Amending Annexes I And III To Council Regulation (EEC) No 2377/90 Laying Down A Community Procedure For The Establishment Of Maximum Residue Limits Of Veterinary Medicinal Products In Foodstuffs Of Animal Origin. Official Journal Of The European Communities.

US Environmental Protection Agency AGENCY, U. E. P. (2014). Food And Drugs. PART 556 - Tolerances For Residues Of New Animal Drugs In Food. Subpart B-Specific Tolerances For Residues Of New Animal Drugs. Electronic Code Of Federal Regulations (Ecfr). Http://Www.Ecfr.Gov/.

Verlinden A, Hesta M, Millet S, Janssens GP (2006). Food Allergy In Dogs And Cats: A Review. Crit Rev Food Sci Nutr 46: 259-273.

White SD, Sequoia D (1989). Food Hypersensitivity In Cats: 14 Cases (1982-1987). J Am Vet Med Assoc 194: 692-695. 